\title{
Associated Risk factors for Postoperative Nosocomial infections among Patients admitted at Felege Hiwot Referral Hospital, Bahir Dar, Northwest Ethiopia
}

\author{
Wondemagegn Mulu ${ }^{1, *}$, Gebre Kibru ${ }^{2}$, Getenet Beyene ${ }^{2}$, Meku Damtie ${ }^{3}$ \\ ${ }^{1}$ Department of Medical Microbiology, Immunology and parasitology, Bahir Dar University, Bahir Dar, Ethiopia \\ ${ }^{2}$ Department of Medical Laboratory Sciences and Pathology, Jimma University \\ ${ }^{3}$ Department of Surgery, Bahir Dar University, Bahir Dar, Ethiopia
}

\section{Email address:}

Wondem_32@yahoo.com(W. Mulu),gtiga@yahoo.com(G. Kibru),rgetenet@yahoo.com(G. Beyene),dmeku@yahoo.com(M. Damtie)

To cite this article:

Wondemagegn Mulu, Gebre Kibru, Getenet Beyene, Meku Damtie. Associated Risk Factors for Postoperative Nosocomial Infections among Patients Admitted at Felege Hiwot Referral Hospital, Bahir Dar, North West Ethiopia. Clinical Medicine Research.

Vol. 2, No. 6, 2013, pp. 140-147. doi: 10.11648/j.cmr.20130206.15

\begin{abstract}
Background: Nosocomial infections are the most challenging problem in all health care systems. In developing countries many people are dying daily due to inadequate health care services of which postoperative infections constitute a large proportion of this burden. Objective: The aim of this study was to identify risk factors associated for post operative nosocomial infections among operated patients at Felege Hiwot Referral Hospital. Methods: A cross-sectional study was conducted on patients who under gone operations from October 2010 to January 2011. A structured questionnaire was used for collection of data on socio-demographic characteristics and associated risk factors. The clinical diagnosis was made by respective surgeons and gynaecologists. Bacterial culture confirmation was done for all patients who developed clinical signs and symptoms of surgical site (SSI) and/or bloodstream infection (BSI) starting from the second day of admission until the time of discharge using standard bacteriological techniques. Bivariate analysis was made to generate to identify associated risk factors. P.value $<0.05$ was considered as stastically significant. Results: A total of 294 patients were included in the study. The rate of postoperative culture confirmed nosocomial infection was $10.9 \%$. The infection rate was higher in females $(11.6 \%)$ than males $(9.4 \%)(\mathrm{OR}=1.27, \mathrm{CI}=0.564-2.863)$. Patients age of $\geq 51$ years old were likely to develop post operative nosocomial infection $(\mathrm{OR}=6.38, \mathrm{CI}=1.156-35.14)$. Patient with underlying diseases $(\mathrm{OR}=2.725, \mathrm{CI}=1.269-5.853)$ and patients who undergone appendectomy ( $\mathrm{OR}=3.1, \mathrm{CI}=1.1-8.3)$ were more likely developed post operative nosocomial infections. Operation duration of $91-150$ minutes $(\mathrm{OR}=11.00, \mathrm{CI}=1.989-60.83)$, and postoperative hospital stay of greater than 15 days $(\mathrm{OR}=82.00, \quad \mathrm{CI}=5.738-1.172)$ were also likely to be risk factor for infection. Conclusion: This study confirmed that advanced age, underlying disease, extended preoperative and postoperative hospital stay, longer duration of surgery and appendectomy were the most likely risk factors for post operative infections. Hence, more attention is required in management of such cases through prior identification of underlying disease, use of effective antibiotics as a prophylaxis and adherence of strict aseptic operating procedures.
\end{abstract}

Keywords: Post operative Nosocomial Infection, Associated Risk Factors, Clean-Operation, Bahirdar, Ethiopia, Clean-Contaminated Operation

\section{Introduction}

Hospital acquired (nosocomial) infections are the most challenging problem in all health care systems [1]. Such infections after surgical procedures can cause pain, poor wound healing, further treatment with antibiotics, increased health care costs, longer hospital stays and increased morbidity and mortality $[1,2]$. It is also recognized as a public health problem world-wide with a prevalence rate of $3.0-20.7 \%$ (3) and an incidence rate of $5-10 \%$ in tertiary care hospitals [4]. In developed countries nosocomial infections (NIs) represent from $5 \%$ to $10 \%$ of total hospitalizations. In the US, estimates range from 25,000 to 100,000 deaths per year as a result of NIs, which represent a yearly burden of over 7.5 billion dollars [5]. In developing countries all over the world, especially in Africa, large numbers of people are dying on daily of preventable and curable diseases due to 
inadequate health care services and postoperative hospital acquired infections constitute a large proportion of this burden [6].

Factors underlying nosocomial post operative infection are multiple and include the type of surgical procedure, the skills of the surgeon, the duration of surgery and the underlying disease of the host [7]. Both infection and wound healing are adversely influenced by poorly controlled diabetes mellitus. Age is considered an important factor, with neonates and the elderly at particular risk of infection [8]. Life style can also impinge on immuno-competency especially stress, alcohol and drug abuse, smoking and lack of exercise or sleep [8].

The actual status of the patient's immune system, environmental factors, extent of contamination during the procedure, organisms shed by the operating room team, the surgical technique and underlying diseases such as diabetes, immunosuppression, irradiation, malnutrition and steroid therapy are other equally important conditions that play an important role for the development of postoperative infection. In addition, the duration of the operation, extremes of age, cigarette smoking, blood transfusions during the postoperative period, deviations from the surgical technique and the use of irrelevant prosthetic materials, supportive treatment administered to the patient in the presence of wound infection (nutritional support, immunotherapy, administration of antibiotics) and the actual immunological parameters of the patient have an effects as well [9-11].

Therefore, the current study was aimed to determine possible risk factors for post-operative hospital-acquired infections at Felege Hiwot Referral Hospital, Bahirdar, North West Ethiopia attempting to draw information that helps for the implementation of better infection prevention practice in the study setting.

\section{Methods}

A cross-sectional study was conducted on patients admitted to assess the risk factors for post operative infection from October 2010 to January 2011 at Felege Hiwot Referral Hospital (FHRH), Bahirdar town, which is located in the distance of $565 \mathrm{~km}$ from Addis Ababa, North West Ethiopia [12]. The hospital has 273 beds and provides different specialized services in four major departments: the Pediatrics, Surgery, Gynaecology and Obstetrics and Internal Medicine. On average 10 major operations were performed per day. The hospital accepts referred patients from different parts of the region and provides local emergency services.

Using a structured questionnaire socio-demographic characteristics and other variables of interest on associated risk factors were collected by face to face interview and patient card review. We included a total of 294 patients who under gone clean and clean-contaminated operations and admitted in Surgical and Gynaecology wards of the hospital during the study period. The clinical diagnosis of the patients was made by surgeons and gynaecologists. Aerobic bacterial culture confirmation was made for all patients who had been developed clinical signs and symptoms of SSI and/or BSI starting from the second day of admission until the time of discharge. All patients who undergone re-operation and who had contaminated and dirty operations, neonates and enrolled patients who showed signs and symptoms of infection within the first 48 hours of admission were excluded from the study.

Data were analyzed using SPSS version16 soft ware. Pearson $\mathrm{X}^{2}$ test and bivariate were used for categorical data to generate $\mathrm{P}$. values and $\mathrm{P}$-value $<0.05$ was considered statistically significant. The ethical clearance of the study was obtained from Ethical Review Board of Jimma University and all the study participants were enrolled after written informed consent was obtained.

The following operational definitions and terms were used:

American Society of Anesthesiologist (ASA) score-I: Normal healthy patient.

ASA score-II: Patient with mild systemic disease that is not incapacitating.

ASA score-III: Patient with severe systemic disease that limits activity but is not incapacitating.

Clean Operations: in which no inflammation is encountered and the respiratory, alimentary or genitourinary tracts are not entered. There is no break in aseptic operating procedure

Clean-contaminated operations: in which the respiratory, alimentary or genitourinary tracts are entered but without significant spillage (without visible contamination).

Contaminated operations: where acute inflammation (without pus) is encountered, or where there is visible contamination of the wound. Examples include gross spillage from a hollow viscous during the operation or compound/open injuries operated within four hrs.

Dirty Operations: in the presence of pus, where there is a previously perforated hollow viscous, or compound/open injuries more than four hours old.

\section{Results}

The gender profile of 294 study participants showed that $96(32.7 \%)$ were males and 198(67.3\%) were females making male to female ratio of $1: 2.1$. The mean age of participant patients was 32.2 years and $280(95.2 \%)$ of them were older than 15 years. The rate of postoperative culture confirmed nosocomial infection (surgical site and blood stream infection) was $10.9 \%$ (Table 1 ). The infection rate among clean and clean-contaminated operation was 3.3\% and $12 \%$ respectively. The observed difference was statistically significant $(\mathrm{P}=0.04, \mathrm{OR}=3.9,95 \% \mathrm{CI}=1.0-17)$ (data not shown).

Nosocomial infection rate was higher in females $23 / 198(11.6 \%)$ than males $9 / 96(9.4 \%)$ but there was no statistical significant difference between the two groups ( $\mathrm{OR}=1.270, \mathrm{CI}=0.564-2.863$ ). Similarly, patients whose age $\geq 51$ years were likely to develop post operative 
nosocomial infection $(\mathrm{OR}=6.375, \mathrm{CI}=1.156-35.14)$ by

bivariate analysis (Table 1).

taking 11-20 years age group as a reference category during

Table 1: Postoperative nosocomial infection rate in relation to sex and age groups of study participants admitted at FHRH, Bahirdar, October -January, 2010/2011.

\begin{tabular}{|c|c|c|c|c|}
\hline \multirow[b]{2}{*}{ Demographic Characters } & \multicolumn{3}{|c|}{ Infection status } & \multirow[b]{2}{*}{ P. value, OR(95\%, CI) } \\
\hline & $\begin{array}{l}\text { Infected } \\
\text { No. (\%) }\end{array}$ & $\begin{array}{l}\text { Not infected } \\
\text { No. }(\%)\end{array}$ & $\begin{array}{l}\text { Total } \\
\text { No. }(\%)\end{array}$ & \\
\hline \multicolumn{5}{|l|}{ Sex } \\
\hline Male & $9(9.4)$ & $87(90.6)$ & $96(32.7)$ & $1 *$ \\
\hline Female & $23(11.6)$ & $175(88.4)$ & $198(67.3)$ & $0.564,1.270(0.564-2.863)$ \\
\hline Total & $32(10.9)$ & $262(89.1)$ & 294(100) & \\
\hline \multicolumn{5}{|l|}{ Age in years } \\
\hline $0-10$ & $1(11.1)$ & $8(88.9)$ & $9(3.1)$ & $0.558,2.125(0.171-26.44)$ \\
\hline $11-20$ & $2(5.6)$ & $34(94.4)$ & $36(12.2)$ & $1 *$ \\
\hline $21-30$ & $18(12.6)$ & $125(85)$ & $143(48.6)$ & $0.245,2.448(0.541-11.07)$ \\
\hline $31-40$ & $2(5.1)$ & 37 (94.9) & $39(13.3)$ & $0.934,0.919(0.123-6.889)$ \\
\hline $41-50$ & $3(6.7)$ & $42(93.3)$ & $45(15.3)$ & $0.837,1.214(0.192-7.688)$ \\
\hline$\geq 51$ & $6(27.3)$ & $16(72.7)$ & $22(7.5)$ & $0.033,6.375(1.156-35.14)$ \\
\hline Total & $32(10.9)$ & $262(89.1)$ & 294(100) & \\
\hline
\end{tabular}

OR: Odds Ratio; CI: Confidence interval; $1 *$ : Reference category

Table 2: Risk factor analysis of post operative nosocomial infections among patients admitted at FHRH, Bahirdar, October - January, $2010 / 2011$.

\begin{tabular}{|c|c|c|c|c|}
\hline \multicolumn{5}{|c|}{ Surgical site infection status } \\
\hline Potential risk factors & $\begin{array}{l}\text { Infected } \\
\text { No. }(\%)\end{array}$ & $\begin{array}{c}\text { Not infected } \\
\text { No. }(\%)\end{array}$ & $\begin{array}{l}\text { Total } \\
\text { No. }(\%) \\
\end{array}$ & P.value, OR $(95 \%$ CI $)$ \\
\hline \multicolumn{5}{|l|}{ ASA score of the patient } \\
\hline ASA class I & $26(9.8)$ & $240(90.2)$ & $266(90.5)$ & \multirow{2}{*}{$\begin{array}{c}1 * \\
0.456,1.538(0.495-4.778)\end{array}$} \\
\hline $\begin{array}{l}\text { ASA class II, III } \\
\text { Underlying disease }\end{array}$ & $4(14.3)$ & $24(85.7)$ & $28(9.5)$ & \\
\hline Diabetes mellitus & $2(66.7)$ & $1(33.3)$ & $3(1)$ & $0.018,18.786(1.651-213.8)$ \\
\hline Anemia & $10(21.7)$ & $36(78.3)$ & $46(15.6)$ & $0.007,3.167(1.372-7.310)$ \\
\hline \multicolumn{5}{|l|}{ Patient life style } \\
\hline Alcoholism & $6(11.5)$ & $46(88.5)$ & $52(17.7)$ & $0.726,1.185(0.458-3.062)$ \\
\hline Stress & $7(10.9)$ & $57(89.1)$ & $64(21.8)$ & $0.827,1.105(0.451-2.706)$ \\
\hline Smoking & $1(20)$ & $4(80)$ & $5(1.7)$ & $0.477,2.241(0.242-20.73)$ \\
\hline \multicolumn{5}{|l|}{ Schedule of surgery } \\
\hline Elective & $4(5.6)$ & $68(94.4)$ & $72(24.5)$ & \multirow{2}{*}{$\begin{array}{c}1^{*} \\
0.143,2.255(0.760-6.695)\end{array}$} \\
\hline Emergency & $26(11.7)$ & $196(88.3)$ & $222(75.5)$ & \\
\hline \multicolumn{5}{|l|}{ Patient preparation } \\
\hline Preoperative bath/shower & $0(0)$ & $2(100)$ & $2(0.7)$ & $0.999,0.000(0.000)$ \\
\hline Preoperative shaving & $0(0)$ & $3(100)$ & $3(1)$ & $0.999,0.000(0.000)$ \\
\hline Presence of drain tube & $2(15.4)$ & $11(84.6)$ & $13(4.4)$ & \multirow{3}{*}{$\begin{array}{l}0.532,1.643(0.346-7.790) \\
0.110,1.944(0.860-4.397) \\
0.020,0.856(0.815-0.889)\end{array}$} \\
\hline Antibiotics usage before surgery & $10(15.7)$ & $54(84.4)$ & $64(21.8)$ & \\
\hline Antibiotic usage after surgery & $30(11.7)$ & $226(88.3)$ & $256(87.1)$ & \\
\hline \multicolumn{5}{|l|}{ No. of extra persons in the OT } \\
\hline $0-8$ & $27(9.9)$ & $247(90.1)$ & $274(93.2)$ & \multirow{2}{*}{$\begin{array}{c}1 * \\
0.467,1.614(0.444-5.865)\end{array}$} \\
\hline $9-15$ & $3(15)$ & $17(85)$ & $20(6.8)$ & \\
\hline \multicolumn{5}{|l|}{ Preoperative hospital stay (days) } \\
\hline$<1$ & $17(11.6)$ & $129(88.4)$ & $146(49.7)$ & $1 *$ \\
\hline $1-5$ & $6(6.6)$ & $85(93.4)$ & $91(31)$ & $0.207,0.536(0.203-1.413)$ \\
\hline
\end{tabular}




\begin{tabular}{|c|c|c|c|c|}
\hline \multirow[b]{2}{*}{ Potential risk factors } & \multicolumn{2}{|c|}{ Surgical site infection status } & \multirow[b]{2}{*}{$\begin{array}{c}\text { Total } \\
\text { No. }(\%) \\
\end{array}$} & \multirow[b]{2}{*}{ P.value, OR $(95 \% \mathrm{CI})$} \\
\hline & $\begin{array}{l}\text { Infected } \\
\text { No. (\%) }\end{array}$ & $\begin{array}{c}\text { Not infected } \\
\text { No. }(\%) \\
\end{array}$ & & \\
\hline $6-10$ & $5(9.3)$ & 49(90.7) & $54(18.4)$ & $0.633,0.774(0.271-2.213)$ \\
\hline $11-15$ & $2(66.7)$ & $1(33.3)$ & $3(1.0)$ & $0.030,15.18(1.306-176.4)$ \\
\hline \multicolumn{5}{|c|}{ Duration of operation (in minutes) } \\
\hline$<30$ & $4(4.3)$ & $88(95.7)$ & $92(31.3)$ & \\
\hline $31-60$ & $20(11.5)$ & $154(88.5)$ & $174(59)$ & $0.063,2.857(0.946-8.626)$ \\
\hline $61-90$ & $3(15.8)$ & $16(84.2)$ & $19(6.5)$ & $0.080,4.125(0.842-20.21)$ \\
\hline $91-150$ & $3(33.3)$ & $6(66.7)$ & $9(3.1)$ & $0.006,11.00(1.989-60.83)$ \\
\hline \multicolumn{5}{|c|}{ Postoperative hospital stay (days) } \\
\hline$<5$ & $1(0.8)$ & $123(99.2)$ & $124(42.2)$ & $1 *$ \\
\hline $5-10$ & $20(13.7)$ & $126(86.3)$ & $146(49.7)$ & $0.004,19.52(2.580-147.7)$ \\
\hline $11-15$ & $7(36.8)$ & $12(63.2)$ & $19(6.5)$ & $0.000,71.75(8.131-633.2)$ \\
\hline$>15$ & $2(40)$ & $3(60)$ & $5(2.4)$ & $0.001,82.00(5.738-1.172)$ \\
\hline Total & $30(10.2)$ & $264(89.8)$ & 294(100) & \\
\hline
\end{tabular}

$\mathrm{ASA}=$ American Society of Anesthesiologist, $\mathrm{OT}=$ operating theater; $1 *$ : Reference category $\quad 4$. Using the Template

The incidence of surgical site infection among patients with and without underlying disease was $17 \%$ and $7 \%$ respectively. The logistic regression analysis was showing that patient with underlying diseases were 2.73 times more likely to develop hospital acquired infections $(\mathrm{OR}=2.725$, $\mathrm{CI}=1.269-5.853$ ) (data not shown). The rates of nosocomial infections among anemic and non anemic patients were $21.7 \%$ and $8.1 \%$ respectively. The difference was statistically significant $(\mathrm{OR}=3.167, \mathrm{CI}=1.372-7.310)$ (Table 2 ). Moreover, the rate (11.7\%) of surgical site infection (SSI) among emergency cases was 2.3 times higher than those who had elective surgery which accounts $5.6 \%$. However, the observed difference was not statistical significant $(\mathrm{OR}=2.26, \mathrm{CI}=0.760-6.695)$ (Table 2$)$.

Nearly $21.8 \%$ of study participants received antibiotics before the day of operation and their treatment were continued for up to 5 days. The incidence of nosocomial infection in those patients who were taking antibiotic prophylaxis was $15.6 \%$. This was much higher than those who did not receive any antimicrobials $(8.7 \%)$. However, the observed difference was not statistically significant $(\mathrm{OR}=1.944, \mathrm{CI}=0.860-4.397)$. Similarly, $87.1 \%$ of patients were received post operative antimicrobial prophylaxis starting from the day of operation of which $11.7 \%$ developed nosocomial infections ( $30 \mathrm{SSI}$ and $5 \mathrm{BSI}$ ) ( $\mathrm{OR}=0.856$, $\mathrm{CI}=0.815-0.899)$ (Table 2).

The duration of hospital stay before operations was from 0 up to 14 days making the average hospital stay of 2.17 days. About $49.7 \%$ of the admitted patients stayed in the hospital for less than one day before get operated of which majority (56.7\%) of patients developed nosocomial infection. However, statistical significant association was observed only for these whose pre-operation hospital stay of 11-15 days $(\mathrm{OR}=15.18, \quad \mathrm{CI}=1.306-176.4)$ by taking preoperative hospital stay $<1$ day as a reference category during bivariate analysis (Table 2).

In this study, most of the operations were completed within 60 minutes. The average duration of surgery was 44.7 minutes with a range of 10 to 150 minutes. The majority $(83.3 \%)$, of the patients who developed nosocomial infection took more than 30 minutes operation time. There was statistical significant association between operation duration of 91-150 minutes and nosocomial infection $(\mathrm{OR}=11.00, \mathrm{CI}=1.989-60.83)$ by taking duration of surgery $<30$ minute as a reference category during bivariate analysis (Table 2).

The post operative hospital stay and hospital acquired infection status of the study participants showed that majority $(96.7 \%)$ of the patients who developed nosocomial infection were stayed for 5-10 days in the hospital. However, statistical significant association was seen between duration of postoperative hospital stay of greater than 15 days and nosocomial infections $(\mathrm{OR}=82.00, \mathrm{CI}=5.738-1.172)$ by taking duration of postoperative hospital stay $<5$ days as reference category during bivariate analysis (Table 2).

The bivariate analysis in this study did not show statistically significant association for tested variables such as American Society of Anesthesiologist (ASA) sore of the patient $\quad(\mathrm{OR}=1.538 \quad(\mathrm{P}=0.456)$, alcoholism $\quad(\mathrm{OR}=1.185$ $(\mathrm{P}=0.726)$, smoking $(\mathrm{OR}=2.241(\mathrm{P}=0.477)$, presence of drain tube $(\mathrm{OR}=1.643(\mathrm{P}=0.532)$, number of person in the OT $(\mathrm{OR}=1.614 \quad(\mathrm{P}=0.467)$ and incidence of surgical site infection (Table 2).

The rates of nosocomial infection were varied with the type of surgical procedures being $26.9 \%$ for patients undergone appendectomy, $20 \%$ and $16.7 \%$ for prostatectomy and amputation respectively (Figure 1). The logistic rigration analysis indicated that patients who undergoing appendectomy was more likely to develop post operative nosocomial infections $(\mathrm{OR}=3.1, \mathrm{CI}=1.1-8.3)$ (data not shown) 


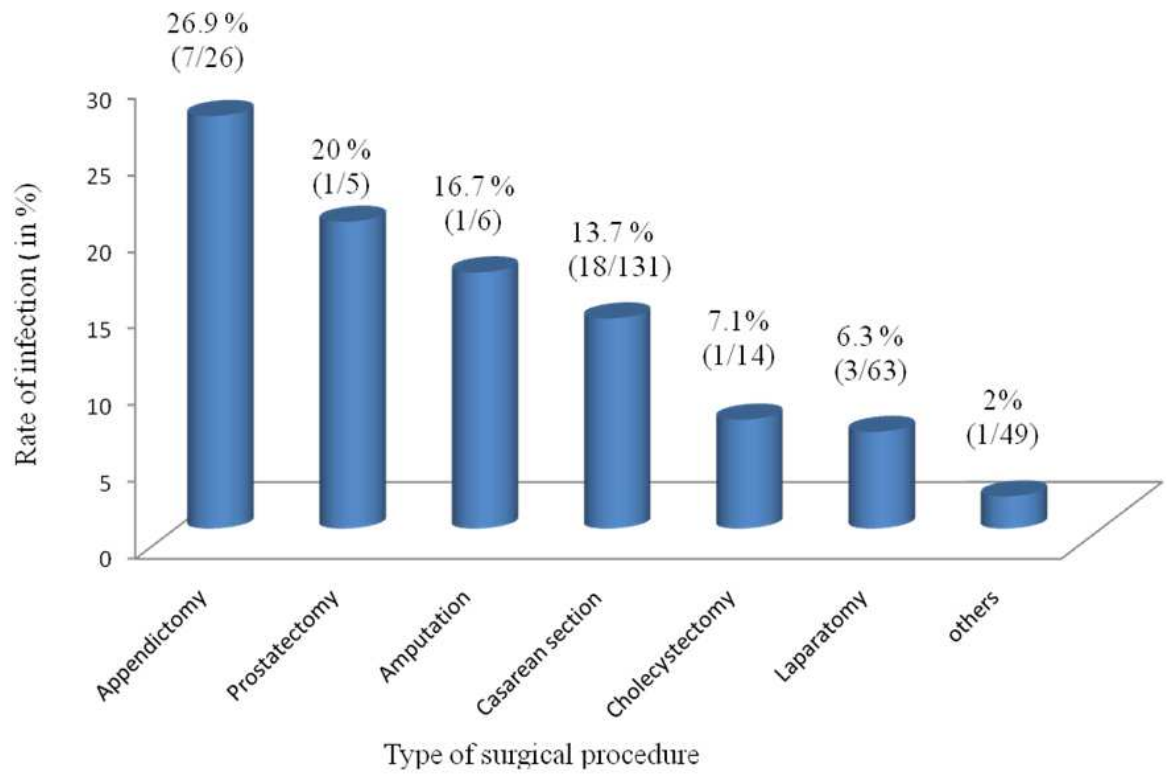

Figure1: The rate of nosocomial infection in relation to type of surgical procedures among admitted patients at FHRH, Bahirdar, October -January, 2010 / 2011

\section{Discussion}

Nosocomial infections, including surgical site infection, still form a large health problem and contribute substantially to patient morbidity, mortality, prolonged hospital stay, expensive hospitalization and prolonged therapy [2, 13, 14]. In the present study, an attempt was made to identify the potential risk factors for post operative infections anticipating better management and control of such infections in the study area. The overall rate of culture confirmed nosocomial infection among these patients was $10.9 \%$ which is comparable to previous studies conducted in Ethiopia [15-18,] where 9 - 14.8\% infection rate were reported. Our findings also agree with different studies carried out in Pakistan [19, 14], India [7, 20, 21] and Mali [22] where the infection rate were $11-13 \%, 9-12 \%$ and $10.2 \%$ respectively.

Our study findings clearly indicated that, as age advances there was an increased incidence of nosocomial infection. However, statistical significant association was seen only on those patients whose age was greater than 50 years old $(\mathrm{OR}=6.375, \mathrm{CI}=1.16-35.14)$. Similar findings have been observed in Nigeria [23], Mali [22], Egypt (24), Pakistan [19, 14], Thailand [25], India [21] and Saudi Arabia [26]. The relative high rate of nosocomial infection among patients above 50 years of age in these studies was could be due to decreased immunocompetence and increased chances of co-morbid factors like diabetes mellitus, hypertension, chronic ailments like asthma, arthritis and malnutrition as it was explained by several authors [19, 27, 23, 25].

Even though there was no significant association between sex and postoperative nosocomial infection in our study, the rate of infection was a bit higher in females $(11.6 \%)$ than males $(9.3 \%)(\mathrm{OR}=1.27, \mathrm{CI}=0.564-2.863)$. This is in agreement with previous study done in India [21], however it disagrees with studies carried out in Thailand [28] where an infection rate of male and female were $24.6 \%$ and $12.9 \%$ respectively and in Pakistan [19] where an infection rate of $11.5 \%$ male and $10.4 \%$ female were reported.

The reports of previous studies [25, 2930$]$ indicated that there was significant association between abnormal American Society of Anesthesiologist (ASA) (II and above) score and surgical site infection rate. Similarly our study showed high rate of surgical site infection among patients with ASA score level II and above. However, the observed difference was not statistically significant ( $\mathrm{OR}=1.538$, $\mathrm{CI}=0.495$ - 4.778).

The rate of surgical site infection in this study showed significant association with those patients having underlying disease condition $(\mathrm{P}=0.010, \mathrm{OR}=2.725,95 \% \mathrm{CI}=1.269$ $5.853)$ which is also indicated in other similar studies $(25$, $31)$. This is by the fact that underlying disease reduces the level of immunity and makes the patient more susceptible to nosocomial infection as it was explained by Luksamijarulkul et al [25].

As a routine practice, pre-operative and postoperative transfusions were carried out for anemic patients to bring the level of hemoglobin to at least $10 \mathrm{gms} / \mathrm{dl}$ in the study setting. In spite of this correction, the rates of nosocomial infections among anemic patients were $21.7 \%$ which showed that being anemic patient was 3.2 times risky to develop nosocomial infection $(\mathrm{OR}=3.167, \mathrm{CI}=1.372-7.310)$ than the non anemic once. Similar findings were reported in Ethiopia [17], Pakistan [19] and Jordan [32]. The reason for association between anemia and surgical site infection is that probably during anemia, most of the hematopoietic system became occupied by the production of red blood cells as a 
result, the production of white blood cells which are important for the immunity will be reduced which in turn makes the wound more vulnerable to infection.

Moreover, significant association between diabetic patients and surgical site infection $(\mathrm{P}=0.018, \mathrm{OR}=18.79$, $95 \% \mathrm{CI}=1.651-213.8) \quad$ was observed in this study is analogous to studies done elsewhere $(19,33,25,21,26)$ but contrast with study conducted in elective general surgery at a public sector medical university in Pakistan [14]. The association between diabetic patients and nosocomial surgical site infection is perhaps due to their low immunity as it was explained formerly [25].

Studies also showed that smoking is one of the significant risk factors for development post operative hospital infections [19, 25, 24]. Similarly the present study demonstrated that smoker patients had 2.24 times chance to develop surgical site infection than non smokers but the observed difference was not statistically significant $(\mathrm{P}=0.477, \mathrm{OR}=2.241,95 \% \mathrm{CI}=0.242-20.73)$. The higher rate of infection among smokers might be due to smoking delays wound healing and impairs the neutrophil defense against surgical pathogens due to decreased oxygenation on the tissue as it was explained by Ahmed et al [19] and Luksamijarulkul et al [25].

Though there was no statistically significant association between schedule of surgery and surgical site infection $(\mathrm{OR}=2.255, \mathrm{CI}=0.760-6.695)$ in this study, the rate of infection was much higher among patients undergone emergency surgery $(11.7 \%)$ than elective surgery $(5.6 \%)$. This finding was similar with previous studies done in Ethiopia [13], Pakistan (19, 14), India (20, 21), Kashmir [7] and Jordan [32]. However, a study done in Southern Iran [31] showed significant association between elective operation and surgical site infection rate. The high rate of infection in emergency cases than elective cases in our study might be due to repeated examination of the patient by health professionals (students) as FHRH is now used as teaching hospital. Moreover, prolonged labour and frequent feotal monitoring by the mother in the case of caesarean section and high rate of contamination from the abdominal cavity during operation also could be the possible reason as it was explained by Chia et al [34].

This study indicated that there was a significant association between patients undergoing appendectomy procedure and incidence of surgical site infection $(\mathrm{OR}=3.1$, $\mathrm{CI}=1.1-8.3$ ). This finding goes in line with a study result of Joyce and Lakshmidevi [21]. The association between appendectomy and rate of surgical site infection is due to the profound contamination of the wound from the flora of the intestinal cavity during operation and may be due to repeated examination of the patient by the health professionals since acute appendectomy is an emergency procedure as previously explained by Chia et al [34].

Presence of drain tube has been found to be a risk factor in some of the previous studies in Ethiopia [15], Iran [27], India [20,35] and Pakistan [14]. The same is true in our study where slightly higher surgical site infection rate in patients having drain tube was identified. However, the presence of drain tube did not show statistical significance association $(\mathrm{P}=0.532, \mathrm{OR}=1.643,95 \% \mathrm{CI}=0.346 \quad-7.790)$. The high rate of infection between the application of drain tube and surgical site infection may be due to the drain itself acted as a portal of entry for pathogenic organisms [35].

In contrary to the common understanding, we have observed that prophylactic routine administration of antibiotics as preoperative and postoperative period did not gave expected protection from postoperative infection. This could be due to increasing drug resistance of bacteria that are known to cause nosocomial infections. Similar observations were made from previous studies conducted in Ethiopia [17], Thailand [25], Southern Iran [31] and India [35]. However, a study conducted by Taye [15] indicated that preoperative antibiotic prophylaxis was found to be highly protective of nosocomial infection.

The stastical association between longer duration of operation and nosocomial surgical site infection rate ( $\mathrm{OR}=11.00, \mathrm{CI}=1.989-60.83$ ) seen in the present study might be due to prolonged duration or exposure of wound during operation makes the wound more vulnerable to contamination by microorganisms either from air or dust particles of the operation theatre or from surgical instruments and members of the surgical team, decreased blood flow and suppressed immunity due to prolonged anesthesia as it was indicated before $(36,35)$. The same results were documented in Egypt [24], Yemen [36], India [19, 20, 35], and Pakistan [19, 14].

Significant relationship between longer preoperative hospital stay and postoperative infection rate $(\mathrm{OR}=15.18$, $\mathrm{CI}=1.306-176.4)$ was also observed in this study. This is because longer preoperative stay increases colonization in patients with hospital acquired pathogenic bacteria which are more resistant to antibiotics as reported by Ganguly et al [35]. Longer stay in hospital also indirectly increases infection rate by lowering patient's resistance as reason given by Ganguly et al [35]. This finding has been supported by several studies conducted elsewhere $[35,21,31,20,14,7$, 19, 24].

Moreover, our study showed a gradual rise in incidence of nosocomial infection as length of postoperative hospital stay increases. Eventually, strong statistical significant association between postoperative hospital stay of $>15$ days and rate of surgical site infection was documented $(\mathrm{OR}=82.00, \mathrm{CI}=5.738-1.172)$. This is related with the study findings that reported higher nosocomial infection rate in patients with a longer post operative stay in hospital than patients having shorter postoperative length of stay [7, 31, 25].

In conclusion, patient related factors (advanced age, the presence of underlying disease), extended preoperative and postoperative hospital stay and longer duration of surgery and appendectomy were the most likely risk factors for postoperative nosocomial infection. Therefore, prior identification of underlying disease, and other related risk factors needs to be made before and after operation for 
appropriate management plan of such patients. Moreover, use of effective antibiotics as a prophylaxis for surgical patients who undergoing clean - contaminated operations and adherence of strict aseptic operating procedure are recommended.

Not including culture for anaerobic bacterial infection and control groups as a comparison were the limitations of these study. However, considering patients who undergone only non- contaminated operations and using both clinical diagnosis by specialists and laboratory confirmation using culture was the strength of this study.

\section{Acknowledgements}

Jimma University is acknowledged for funding the project, Amhara Region Health Bureau, Felege Hiwot Referral Hospital, and Bahirdar Regional Laboratory for allowing us to conduct

\section{References}

[1] Babkin Y, Raveh D, Lifschitz M. Incidence and risk factors for surgical infection after total knee replacement. Scand $J$ Infect Dis. 2007; 39: 890 - 895.

[2] Torpy MJ, Burke EA, Glass MR. Postoperative infections. JAM. 2010; 303: 25-44.

[3] Samuel SO, Kayode OO, Musa O et al. Nosocomial infections and the challenges of control in developing countries. Afr. J. Cln. Exper. Microbiol. 2010; 11: 102-110.

[4] Jain A, Singh K. Recent advances in the management of nosocomial infections. JK Sci. 2007; 9: 3-8.

[5] Duque SA, Ferreira FA, Cezário CR. Nosocomial infections in two hospitals in Uberlandia, Brazil. Rev Panam Infectol. 2007; 9: 14-18

[6] Messele G, Woldemedhin Y, Demissie M, et al. Common causes of nosocomial infections and their susceptibility patterns in two hospitals in Addis Ababa. Ethiop. J. Health Biomed Sci.2009; 2:3-8.

[7] Mustafa A, Burkhari A, kakru KD. Incidence of nosocomial wound infection in postoperative patients at a teaching hospital in Kashmir. Jk practitioner.2004; 11: 38-40.

[8] Cooper RA. Identifying criteria for wound infection. Understanding wound infection. London. 2005. Available at: http://ewma.org/fileadmin/user_upload/EWMA $/$ pdf/position document/2005 Wound Infection/English pos_doc_final.pdf. Accessed on: June14, 2010.

[9] WHO. Prevention of hospital acquired infections: A practical guide. Malta: Department of Communicable Disease, Surveillance and response; 2002. Available at http://www.who.int/csr/resources/publications/whocdscsrep h 200212.pdf. Accessed on: July 20, 2010.

[10] Kollef MH, Sharpless L, Vlasnik J et al. The impact of nosocomial infections on patient outcomes following cardiac surgery. Chest. 1997; 112: 666-675.

[11] Akyurek N, Kerek M, Yuksel O, et al. Turk j med sci. 2000;
30: $275-280$.

[12] Rasnake SM, Dooley PD. Culture-negative surgical site infections. 2006; 7: 55-565.

[13] Gedebou M, Kronvall G, Habte-Gabr E et al. The bacteriology of nosocomial infections at Tikur Anbessa Teaching Hospital, Addis Ababa. Acta Pathol Microbiol Immunol Scand (B).1987; 95:331-336.

[14] Sangrasi KA, Leghari A, Memon A. Surgical site infection rate and associated risk factors in elective general surgery at a public sector medical university in Pakistan. Int WJ. 2008; 5: 74-78.

[15] Taye M. Wound infection in Tikur Anbessa Hospital, surgical department. Ethiop Med J. 2005; 43:167-74.

[16] Gedebou M, Habte-Gabr E, Kronvall G et al. Hospital-acquired infections among obstetric and gynecological patients at Tikur Anbessa Hospital, Addis Ababa. J Hosp Infect.1988; 11: 50-9.

[17] Habte-Gabr E, Gedebou M, Kronvall G. Hospital-acquired infections among surgical patients in Tikur Anbessa Hospital, Addis Ababa, Ethiopia. AMJ Infect control. 1988; 16: 7- 13.

[18] Tesfahunegn Z, Asrat D, Woldeamanuel Y, Estifanos K. Bacteriology of surgical site and catheter related urinary tract infections among patients admitted in Mekelle Hospital. Ethiop.Med. J. 2009; 47: 117-27.

[19] Ahmed M, Alam NS, Manzar SO. Post-operative wound infection: a surgeon's dilemma. Pakistan J Surg. 2007; 23: 41-47.

[20] Lilani PS, Janagale N, Chowdhar A et al. Surgical site infection in clean \& clean- contaminated cases. Indian $J$ Micro Biol. 2005; 23: 249-52.

[21] Joyce S, Lakshmidevi N. Surgical site infections: Assessing risk factors, outcomes and antimicrobial sensitivity patterns. Afr. J. Microbiol. Res. 2009; 3:175-179.

[22] Togo A, Traore A, Kante L, et al. Fighting nosocomial infection rates in the general surgery department of the teaching hospital Gabriel Toure in Bamako, Mali. The $O p$ Biol J. 2010; 3: 87-91.

[23] Isibor OJ, Oseni A, Eyaufe A. Incidence of aerobic bacteria and Candida albicans in post operative wound infections. Afr.J. microbiol. Res. 2008; 2: 288-291.

[24] Abdel-Haleim KM, Ibrahim ZA, El-Tahl EM. Surgical site infections and associated risk factors in Egyptian orthopedic patients. J Am Sci. 2010; 6: 272-280.

[25] Luksamijarulkul $P$, Parikumsil $P$, Oomsuwan VN. Nosocomial surgical site infection among Photharam hospital patients with surgery: Incidence, risk factors and development of risk screening form. J Med Assoc Thai. 2006; 89: 81-9.

[26] El-Awady MY, Harak MK, Abdelrahman AA, et al. Hospital acquired infections in Madinah- Ksa: epidemiology and intervention for reduction. J Med Biomed Sci. 2010; 42- 47.

[27] Shojaei H, Borjian S, Shooshtari JP et al. Surveillance of clean surgical procedures: an indicator of to establish a base line of a hospital infection problem in developing country, Iran. Indian J Surg. 2006; 68: 89-92. 
[28] Emori TG, Gaynes R. An overview of nosocomial infections, including the role of the Microbiology laboratory, in Atlanta, Georgia. Clin Microbiol Rev. 1993; 6: 428-442.

[29] Pryor R \& Messmer PR. The effect of traffic pattern in the OR on surgical site infections. AORN J68.1998; 68: 649-660.

[30] Ashton J, Morton N, Beswick S. Wound care guide lines. Nurswc 001. 2010; 1-43.

[31] Kavari SH, Rasekhi AR. Surgical site infections: Incidence and risk factors at Southern Iran Hospitals. Middle East J Int Med. 2008; 1:1-7.

[32] Kaplan MN, Smadi AA, Al-Taani IM. Microbiology of wound infection after caesarean section in a Jordanian hospital. East Med Health J. 2003; 9: 1068-1074.
[33] Wukich KD, Lowery JN, McMillen LR. Comparison of patients with and without diabetes mellitus. J Bone Joint Surg Am. 2010; 92: 287-295.

[34] Chia JY, Tan KW, Tan Y. A survey of postoperative wound infections in Obstetrics and Gynecology. The kandang kerabu hospital experience. Singapore Med J.1993; 34: 221224

[35] Ganguly PS, Khan Y, Malik A. Nosocomial infections and hospital procedures. Indian community Med. 2000; xxv: $39-43$.

[36] Rajaa AY, Salam RA, Salih AY. Rate and risk factors of surgical site infections with antibiotic prophylaxis. Saudi Med J. 2002; 23: 672-674. 